\title{
Editorial
}

\section{Resolución de conflictos, política educativa, estado de derecho, y geopolítica: Pasado y presente}

\author{
Daniel Javier, de la Garza Montemayor \\ Editor Revista Política, Globalidad y Ciudadanía \\ https://orcid.org/0000-0001-6962-9059 \\ https://doi.org/10.29105/pgc6.12-1
}

Como referenciar la editorial:

De la Garza Montemayor, D. J. (2020). Resolución de conflictos, política educativa, estado de derecho, y geopolítica: Pasado y presente. Revista Política, Globalidad y Ciudadania, 1214. Recuperado de http://revpoliticas.uanl.mx/index.php/RPGyC/article/view/157

En la actualidad, el mundo vive grandes desafíos en materia de salud pública, pero también de encontrar nuevas fórmulas de desarrollo económico. Los sistemas políticos de naciones diversas tienen el reto de encontrar soluciones sostenibles que cumplan con las expectativas de las naciones (Zamorano Farías, 2010).

En el presente número de la revista "Política, Globalidad y Ciudadanía", el lector tendrá acceso a once artículos que profundizan sobre temas que son indispensables para encontrar los mecanismos institucionales que permitan una mejor convivencia social entre los individuos que forman parte de una sociedad plural y también entre las naciones. Corresponden a estudios que se han realizado de manera rigurosa y con una examinación de casos que contribuyen a un necesario debate en la academia actual.

Al respecto, resulta importante reflexionar sobre el concepto de una democracia de "calidad" en la que O'Donnell, Vargas y Iazzetta (2004) establecieron que existen algunos elementos esenciales que nos permiten hablar de una democracia con contenido. Este concepto, se compone entre otras cosas, por la celebración de elecciones libres, por una verdadera independencia de los medios de comunicación, por contar con índices aceptables en materia de equidad, por el hecho de que la población tenga acceso a una amplia seguridad social y porque las mayorías y minorías se encuentren representadas.

Por esa misma razón, es importante que las instituciones puedan convertirse en un mecanismo eficaz que pueda hacer posible que esos ideales de una democracia de calidad se conviertan en una realidad cotidiana. De acuerdo con un estudio de Tusell (2015), algunos de los factores que se encuentran inherentemente relacionados con la calidad de la democracia son la rendición de cuentas y el estado de derecho. 
En términos generales, este es uno de los principales conceptos que nos concierne en la presente edición: el funcionamiento correcto de los poderes públicos resulta clave en la consolidación de cualquier régimen democrático y en particular, en el de preservar las libertades fundamentales (Barreda, 2010).

En materia de mediación, se cuenta con un estudio cualitativo por parte de Roberto Guerrero Vega, de la Universidad Politécnica de Nicaragua, quien propone un modelo de evaluación de la calidad al servicio de mediación en México. Es necesario resaltar que son investigaciones como las de Guerrero Vega, las que contribuyen a fijar las bases de una mejoría en la resolución de controversias, las mismas que contribuyen a generar una mejor convivencia social. Precisamente sobre el tema del bienestar, es que Francisco Gorjón Gómez, de la Universidad Autónoma de Nuevo León (México), nos presenta un trabajo que permite corroborar la presencia de la mediación como un instrumento para lograr el bienestar colectivo.

En cuanto al análisis jurídico, se presentan las indagaciones de Yahaira Berenice Martínez-Pérez, Brenda Judith Sauceda-Villeda y María Salomé Moreno-Rodríguez de la Universidad Autónoma de Nuevo León (México), quienes argumentan a favor de una reforma jurídica que protega a los sectores más vulnerables. Además se cuenta con la participación de Jose Luis Leal Espinosa, de la Universidad Autónoma de Coahuila (México), quien también argumenta de manera sólida en torno a la necesidad de concretar mecanismos institucionales que garanticen el derecho a la información.

En materia educativa, contamos con las destacadas participaciones de Fabio Orlando Cruz Paez y Oswaldo Vanegas Florez de la Universidad de Cundinamarca (Colombia) y el caso de Fernando Cárdenas Cabello del Centro Universitario CIFE (México), quienes nos exponen sobre el proceso de vigilancia tecnológica y su incidencia en la cultura organizacional de una prestigiada universidad colombiana en el primer caso, mientras que en el segundo se examina la adecuación de la política industrial 4.0 en la transición de un gobierno a otro, basado en el análisis del Plan Nacional de Desarrollo. También los investigadores de la Universidad de la Costa, Greys Nuñez Ríos, Kadry García Mendoza, Judith Castillo Martelo y Nevis Niño-Jiménez quienes realizan un estudio sobre una intervención comunitaria de cómo se puede motivar a los ciudadanos a participar en actividades que contribuyan a la paz.

En materia geopolítica, esta edición cuenta con dos productos notables: El análisis de la relación de la Alianza del Pacífico, que conforma México, Perú, Chile y Colombia, con la República Popular China, que realiza el investigador de la Universidad Autónoma de San Luis Potosí (México), Flavio Rafael González-Ayala. El lector también puede consultar la investigación interinstitucional de José María Ramos García (El Colegio de la Frontera Norte, México), Carlos Barrachina Lisón (Universidad Anáhuac, México) y Jimmy Emmanuel Ramos (Universidad 
Autónoma de Baja California), quienes ponderan sobre los retos de la frontera sur de México, en cuanto a su importancia en su relación con Estados Unidos.

Por último, la edición cuenta con contribuciones internacionales notables sobre temas actuales y también, de una introspección de la evolución de un partido político que ha sido fundamental para la democracia española: En ellos se encuentra reflejado el compromiso de la revista Política, Globalidad y Ciudadanía de difundir proyectos de investigación de temas vigentes, así como aquellos que contienen una oportuna revisión histórica.

En lo relacionado al tema se encuentra con una vigencia oportuna, el trabajo de Juan Sebastián Sánchez Gómez (Universidad de los Andes, Colombia) quien expone el caso del estado de excepción decretado en Colombia a partir de la pandemia de coronavirus. En el caso de Borja García-Vázquez (Universidad Autónoma de Nuevo León), se realiza un amplio recorrido del Partido Socialista Obrero Español (PSOE), desde un año antes de la muerte de Francisco Franco, al año de su primera derrota electoral a nivel nacional, después de detentar el poder por 14 años consecutivos.

En síntesis, el fascículo 6(12) cuenta con artículos de investigadores de prestigio, de centros educativos también destacados, que reflexionan de temas fundamentales que refuezan las líneas de investigación vigentes en materia de geopolítica, mediación, estado de derecho y política educativa. Por lo tanto nuestra intención es contribuir al intercambio permanente en materia de investigación de calidad, es por esto que esperamos que los académicos que consulten esta edición puedan encontrar información que les sea de utilidad en sus propias indagaciones.

\section{REFERENCIAS}

Barreda, M. (2010). La calidad de la democracia: Un análisis comparado de América Latina. Política y gobierno, 13(2), 265-295.

O' Donnell, G., Vargas, J. e Iazzetta, O. (2004). The Quality of Democracy: Theory and Applications. Notre Dame: The University of Notre Dame Press.

Tusell, A. (2015). La calidad de la democracia y sus factores determinantes. Un análisis comparado de 60 países. Política y Sociedad, 52(1), 179-204. doi: http://dx.doi.org/10.5209/ rev_POSO.2015.v1.n52.45786

Zamorano Farías, R. (2010). El sistema político como institucionalización de las expectativas. Boletín Mexicano de Derecho Comparado,43(128),895-921. 